THEORY AND METHODS

\title{
Is the link between alcohol and cardiovascular death among young Russian men attributable to misclassification of acute alcohol intoxication? Evidence from the city of Izhevsk
}

\author{
V M Shkolnikov, M McKee, V V Chervyakov, N A Kyrianov
}

J Epidemiol Community Health 2002;56:171-175

See end of article for authors' affiliations

Correspondence to Professor M McKee European Centre on Health of Societies in Transition, London School of Hygiene and Tropical Medicine, Keppel Street, London WCIE 7HT, UK.

martin.mckee@lshtm.ac.uk

Accepted for publication 15 November 2001

\begin{abstract}
Background: Research on the aetiology of sudden cardiac death among young men in Russia strongly suggests an association with binge drinking. However, the possibility remains that such deaths are misclassified as being attributable to cardiovascular disease when they are really caused by acute alcohol poisoning.

Objective: To describe postmortem levels of blood alcohol in Russian men dying from various causes and so determine whether deaths from alcohol poisoning are being misclassified as cardiovascular deaths.

Setting: Ishevsk, capital of the Udmurt Republic, situated in the Ural region of the Russian Federation. Methods: The study was part of a larger one on adult mortality. The study sample was 309 deaths among men aged 20-55 dying between August 1998 and March 1999 from other than neoplasms, infectious diseases or unspecified causes and on whom necropsy records could be obtained. Information on cause of death was extracted from death certificates and data on postmortem blood alcohol concentration (BAC) from forensic records. Blood alcohol concentrations were adjusted where necessary to allow for delay in necropsy.

Results: Medium or greater levels of intoxication occurred in a quarter of those recorded as dying from cardiovascular disease but in over half of those dying from external causes. BAC levels consistent with at least strong intoxication were seen in $13.5 \%$ of deaths from cardiovascular disease and $27.1 \%$ from external causes. No cardiovascular deaths had BAC at levels usually thought to be fatal while this level was seen in $26 \%$ of deaths from accidental poisoning.

Conclusion: Evidence of recent consumption of alcohol is common among Russian men dying under the age of 55, with severe intoxication common where death is from external causes. However, the high death rates from cardiovascular disease in Russia cannot be explained by misclassification of deaths attributable to acute alcohol poisoning. This study thus resolves one of the outstanding controversies in the story of alcohol and cardiovascular disease in the former Soviet Union.
\end{abstract}

A growing body of evidence links alcohol with the large fluctuations in mortality in Russia since the mid1980s. ${ }^{1-3}$ A causal relation with deaths from alcohol poisoning and from violence is uncontroversial. However, in Russia there is also a close correlation between alcohol and cardiovascular deaths. During the anti-alcohol campaign of the mid-1980s the death rate from cardiovascular diseases underwent a sudden fall, with a subsequent increase in the late 1980s and early 1990s when alcohol consumption was rising. ${ }^{1}$ The amplitude of the fluctuation reached $\pm 40 \%$ of the underlying mortality rates between the ages of 30 and 55, although the changes were much smaller at older ages. This immediate response in cardiovascular mortality to a change in alcohol consumption is unexpected and especially problematic, given the well known cardioprotective effect of alcohol. ${ }^{4}$

Elsewhere we have argued that this phenomenon may be attributable to binge drinking, which is common in Russia. This is known to increase the risk of sudden cardiac death, ${ }^{5}$ a mode of cardiovascular death more frequent in this region than in the west, ${ }^{6}$ by means of physiological responses to alcohol that differ markedly from those seen with regular moderate consumption. ${ }^{7}$ This view has, however, been challenged. ${ }^{8}$ Many objections have been dealt with elsewhere ${ }^{9}$ but one remains. This is that the apparent correlation between alcohol consumption and cardiovascular mortality arises because a substantial proportion of deaths among middle aged adults that are recorded as sudden cardiac death are actually attributable to acute alcohol related conditions such as poisoning by alcohol, perhaps to reduce the social stigma involved.

A study in 1991 in Kursk reported that many deaths attributed to "other forms of ischaemic heart disease" and "other heart diseases" had lethal or nearly lethal blood alcohol levels. ${ }^{10}$ Unfortunately, it gave few details of subjects or methods.

If the aetiology of cardiovascular disease in Russia is to be understood it is essential to study the problem of a possible overreporting of cardiovascular deaths. This requires in depth validation studies. This paper contributes to this process by reporting blood alcohol concentrations among men dying at age of 20 and 55, whose deaths were attributed to cardiovascular disease or to causes conventionally associated with alcohol consumption, especially injuries and violence.

\section{DATA AND METHODS}

The study is set in Izhevsk, capital of the Udmurt Republic, one of the leading industrial centres in the Urals, with mortality close to the Russian average. ${ }^{11}$ This study was part of a larger study ${ }^{11}$ that used verbal necropsy ${ }^{12}$ to ascertain circumstances leading to death among young and middle aged men.

The larger sample from which the cases presented here were drawn was of 594 male deaths from causes other than 
Table 1 Structure of the study sample by age and cause of death in relation to larger sets of male deaths: five major cities* of the Udmurt Republic, age 20-55, deaths from neoplasms, infectious diseases and ill defined causes excluded. Data shown as precentages

\begin{tabular}{|c|c|c|c|c|}
\hline & $\begin{array}{l}\text { All deaths in } 1998 \text { and the } \\
\text { first } 6 \text { months of } 1999 \\
(n=2898)\end{array}$ & $\begin{array}{l}\text { All deaths in } 1998 \text { and the } \\
\text { first } 6 \text { months of } 1999 \text { with } \\
\text { complete necropsy results } \\
(n=2598)\end{array}$ & $\begin{array}{l}\text { Verbal necropsy study } \\
(\mathrm{n}=594)\end{array}$ & $\begin{array}{l}\text { Study sample } \\
(n=309)\end{array}$ \\
\hline Age 20-39 & 42 & 45 & 38 & 42 \\
\hline Age $40-55$ & 58 & 55 & 62 & 58 \\
\hline Cardiovascular diseases & 33 & 30 & 37 & 29 \\
\hline External causes & 54 & 66 & 54 & 64 \\
\hline Other causes & 13 & 4 & 9 & 7 \\
\hline
\end{tabular}

neoplasms, infectious diseases, and ill defined causes, for whom it had been possible to identify key informants. It had been drawn from a complete set of all deaths from 1 August 1998 to 31 March 1999 among men aged 20 to 55 living in five major cities of the Udmurt Republic (Izhevsk, Votkinsk, Sarapul, Glazov, Kambarka). It was broadly representative of all eligible deaths in terms of age, classes of causes of death, ethnic and educational composition. ${ }^{11}{ }^{13}$ There was some inevitable bias compared with all potentially eligible deaths because of the requirement to identify key informants. Thus there was overrepresentation of married men $70 \%$ in the sample versus $65 \%$ in all eligible deaths) and underrepresentation of divorced men ( $11 \%$ versus $14 \%$, respectively). It is also probable that socially isolated men and those leading a marginal existence were underrepresented.

The sample used in this study was a subset of the 594 cases, selected by the ability to obtain to obtain complete necropsy reports from the regional forensic medicine department situated in the city of Izhevsk. It consisted of 309 cases (56\% of the larger sample).

Table 1 compares the age distribution and percentages of deaths from external and cardiovascular causes in the different populations: all deaths at age 20-55 in the five cities of the Udmurt Republic from causes other than neoplasms, infectious diseases, and ill defined conditions (2898 deaths); all deaths with complete necropsy results (2598 deaths); deaths used in the verbal necropsy study (594 deaths); and those in present study (309 deaths). The final sample of deaths is similar to that of all deaths undergoing necropsy. External causes of death are, however, somewhat overrepresented among deaths undergoing necropsy, which is inevitable because it reflects the current indications for conducting necropsies.

As variation in necropsy rates could introduce bias, a brief description of current procedures is necessary. In the Soviet era all deaths under age 60 had to undergo necropsy. Thus, in the 1980s the rate of necropsy was almost $100 \%$ at working ages. New regulations set out in the Health Ministry's directive 84 of 29 April 1994 made it possible, in certain circumstances (religious beliefs, explicit will of deceased, request of relatives) not to undergo necropsy. ${ }^{14}$ However, necropsy remains obligatory in all cases where the diagnosis is not clear or violence is suspected. In fact, among all male deaths in Udmurtia at ages 20 to 55 occurring during 1998 and the first half of the 1999 (5148 deaths) the necropsy rate was still high (82\%). Among deaths from causes other than neoplasms, infectious diseases, and ill defined causes occurring in the five cities (2898 deaths) it is $89 \%$. It is especially high for deaths at young ages, reaching $95 \%$ for deaths at age $20-39$, falling only to $85 \%$ at age 40-55. It was almost $100 \%$ for deaths from external causes (only four deaths without necropsy) and $81 \%$ for deaths from cardiovascular diseases.

For all male deaths in the cities studied at age 20-55, other than those from neoplasms, infectious diseases, and ill defined causes (2898 deaths), 73\% of medical death certificates were issued by forensic pathologists, $14 \%$ by hospital pathologists, and $13 \%$ by other physicians. In the study sample, in contrast, $99 \%$ of death certificates were issued by forensic experts.

Causes of death were obtained from civil death certificates, used to generate routine mortality statistics. Statisticians in the regional statistical office code principal cause of death on civil death certificates by applying the brief Russian classification of causes of death to the ICD codes and basic narrative information listing multiple causes (immediate, intermediate, underlying and complementary causes) on medical death certificates. An earlier study in which we recoded the principal cause of death on a sample of 1023 matched medical and civil death certificates relating to male deaths at age 20-55 ${ }^{11}$ showed very little disagreement in terms of the ICD classes of causes of death. That is to say that if a death is classified as a death from cardiovascular disease or from an external cause than it is very unlikely that such a death would be found to be in another class of causes of death.

Alcohol was measured by gas chromatography from blood taken routinely at necropsy. Necropsies are usually completed within two days after death. If not, an established formula is used to take account of tissue decay.

Norms established in the USSR in 1977, updated in Russia in 1996, ${ }^{15}$ were applied: under $30 \mathrm{mg} / \mathrm{dl}$-no adverse health effects; $30-50 \mathrm{mg} / \mathrm{dl}$-insignificant intoxication; $50-149 \mathrm{mg} /$ dl-slight intoxication; 150-249 mg/dl-medium intoxication; 250-299 mg/dl—strong intoxication; 300-499 mg/dladvanced and potentially lethal intoxication; and above 500 $\mathrm{mg} / \mathrm{dl}-\mathrm{lethal}$. These are broadly comparable with views in the west. ${ }^{16}$ We took the midpoint of the potentially lethal band, $400 \mathrm{mg} / \mathrm{dl}$, as where death was probable attributable to alcohol poisoning.

\section{RESULTS}

Some $61.8 \%$ deaths had more than none or insignificant levels of blood alcohol. Table 2 shows that $42.7 \%$ of deaths had medium intoxication or above (that is, $150 \mathrm{mg} / \mathrm{dl}$ and higher) and $22 \%$ in strong or advanced intoxication (that is, above 250 $\mathrm{mg} / \mathrm{dl}$ ). Thus, many Russian men who die at this age are intoxicated at the time of death. No men dying from cardiovascular disease had blood alcohol concentrations in excess of $400 \mathrm{mg} / \mathrm{dl}$ although $5.6 \%$ had concentrations above $300 \mathrm{mg} / \mathrm{dl}$ while corresponding figures for external causes were $5 \%$ and $16 \%$ respectively. Fourteen per cent of deaths from cardiovascular causes had levels consistent with strong intoxication, although a quarter had levels consistent with moderate intoxication.

Nearly all cardiovascular deaths with significant quantities of alcohol detected were ascribed to "Other forms of ischaemic heart disease without hypertensive disease" or "Other heart diseases" (using the Russian classification of causes of death). The first group includes deaths attributable to atherosclerosis, acute forms of ischaemic heart disease other than myocardial infarction including ill defined acute ischaemic heart disease; the second group includes cardiomyopathies, cardiac arrhythmias, myocarditis, pericarditis, conduction disorders and heart failure. 
Table 2 Distribution of the deceased by blood alcohol concentration (BAC) and by cause of death, for 309 male deaths at ages 20-55 in the city of Izhevsk, 1998-1999

\begin{tabular}{|c|c|c|c|c|}
\hline \multirow[b]{2}{*}{ Cause of death } & \multicolumn{4}{|c|}{ Number of deaths ( $\%$ of row total) } \\
\hline & Total & $\begin{array}{l}\text { Of which BAC } \\
>150 \mathrm{mg} / \mathrm{dl}\end{array}$ & $\begin{array}{l}\text { Of which BAC } \\
>250 \mathrm{mg} / \mathrm{dl}\end{array}$ & $\begin{array}{l}\text { Of which BAC } \\
>400 \mathrm{mg} / \mathrm{dl}\end{array}$ \\
\hline \multicolumn{4}{|l|}{ Of which: } & 0 \\
\hline Other forms of ischaemic heart disease* & 40 & $13(32.5)$ & $7(17.5)$ & 0 \\
\hline Other heart diseases $\dagger$ & 22 & $8(36.4)$ & $5(22.7)$ & 0 \\
\hline $\begin{array}{l}\text { External causes of death } \\
\text { Of which: }\end{array}$ & 199 & $104(52.3)$ & $54(27.1)$ & $10(5.0)$ \\
\hline Road vehicle accident & 22 & $8(36.4)$ & $2(9.1)$ & $1(4.5)$ \\
\hline Accidental poisonings & 27 & $20(74.1)$ & $18(66.7)$ & 7 (25.9) \\
\hline Fire related accident & 6 & $4(66.7)$ & $1(16.7)$ & 0 \\
\hline Accidental drowning & 6 & $3(50)$ & $2(33.3)$ & 0 \\
\hline Suicide & 69 & $30(43.5)$ & $10(14.5)$ & $2(2.9)$ \\
\hline Homicide & 31 & $17(54.8)$ & $4(12.9)$ & 0 \\
\hline III defined violent cause & 5 & $2(40)$ & $2(40)$ & 0 \\
\hline $\begin{array}{l}\text { Other diseases } \\
\text { Of which: }\end{array}$ & 21 & $6(28.6)$ & $3(14.3)$ & 0 \\
\hline Chronic alcoholism & 6 & $4(66.7)$ & 2 (33.3) & 0 \\
\hline All causes combined & 309 & $132(42.7)$ & $69(22.3)$ & $10(3.2)$ \\
\hline $\begin{array}{l}\text { *In 1998: item } 95 \text { of the former Russian } \\
414 \text { in ICD-9. In } 1999 \text { : items } 127 \text { and } \\
\text { corresponding to items I20, I24-I25 in I } \\
\text { causes of death corresponding to items } \\
\text { classification of causes of death corresp }\end{array}$ & $\begin{array}{l}\text { ssificat } \\
\text { of the } \\
10 \text {; ti } \\
-429\end{array}$ & $\begin{array}{l}\text { causes of deat } \\
\text { nt Russian class } \\
\text { 8: items 96-97 } \\
\text {-9. In 1999: ite } \\
26-128,130-15\end{array}$ & $\begin{array}{l}\text { orresponding to } \\
\text { ation of causes } \\
\text { the former Russ } \\
131-132 \text { of th } \\
\text { ICD-10. }\end{array}$ & $\begin{array}{l}\text { ms } 411 \text { and } \\
\text { death } \\
\text { classification of } \\
\text { urrent Russian }\end{array}$ \\
\hline
\end{tabular}

In contrast, advanced intoxication was more common in deaths from external causes, over half of whom had levels consistent with moderate intoxication and over a quarter with severe intoxication. Rates were especially high for accidental poisoning by alcohol, which included most cases with very high levels. The relative rarity of intoxication in deaths from motor vehicle accidents is plausibly attributable to those who had not been drinking being killed by those who had.

\section{DISCUSSION}

This study does not support the argument that most young and middle aged Russian men, whose deaths are ascribed to cardiovascular disease, are in reality killed simply by alcohol poisoning. It does confirm the high frequency of intoxication among those dying in this age group, although the immediate cause of death is commonly alcohol poisoning or injury.

The proposed role of alcohol in cardiovascular death requires a brief explanation. While we argue that binge drinking is causally associated with sudden cardiac death, the physiological pathways do not require that death will necessarily occur during a binge. The threshold for ventricular irritability is reduced after recovery from a binge ${ }^{17}$ and changes in blood coaguability are most adverse after cessation of heavy drinking. ${ }^{18}$ Thus, the findings that many of those dying have been drinking, but are not fatally intoxicated, is entirely consistent with the proposed mechanisms.

Research on this topic, and in this setting, is not easy and, inevitably, the findings are subject to many limitations. It was retrospective so blood samples were not taken under standardised conditions, although this would anyway have been difficult because of differing intervals before bodies were transmitted to pathologists. Recorded levels could plausibly overestimate values at death because of postmortem production of alcohol but this would not affect our conclusions. It is also possible that metabolism of alcohol after cessation of drinking could produce lower levels postmortem than were present at the onset of illness or injury. Superficially this seems more likely to be able to challenge our conclusion, and

\section{Key points}

- Although there is now considerable evidence to link binge drinking with the high rates of cardiovascular disease, in particular sudden cardiac death, in Russia, a counterargument is that the apparent association may arise because of misclassification of deaths from acute alcohol poisoning.

- This study, in which postmortem blood alcohol concentrations were measured in young Russian men, shows that this is not the case, and while many of those dying from cardiovascular disease have been drinking, the levels are not sufficient to cause death from acute alcohol poisoning.

\section{Policy implications}

This study dispels one of the remaining objections to the argument that alcohol is a major factor in the high rate of cardiovascular disease in the former Soviet Union and strengthens the case for an effective policy response to this major cause of premature death.

it would certainly suggest that the true level of intoxication in those dying from injury, where survival is more probable, is higher than in our results. However, it would require that men dying from alcohol poisoning lived long enough for their blood levels to fall to those consistent with only moderate intoxication, at which stage they died. On the basis of published rates of alcohol breakdown, this is likely to take about 8-10 hours. ${ }^{19}$ While not inconceivable, it seems implausible that this would be a sufficiently common situation. It is unlikely to be sufficient to explain the very much higher Russian death rate (515 deaths/100 000 in Russia in 1996 compared with 162/100 000 in the European Union) ${ }^{20}$ as being attributable, to any significant extent, to misclassification of deaths attributable to alcohol poisoning. 
Obviously these findings can only be extended to other parts of Russia with caution. Izhevsk and its neighbouring Udmurt cities are typical of the urban population of Russia in terms of patterns of mortality, economic indicators, and sociodemographic composition. However, it must be accepted that medical diagnosis and practices involved in cause of death coding and necropsy may differ significantly between Russian regions.

Clearly more research is required to understand why premature cardiovascular death is so common among Russians. However, in the light of the present results the high cardiovascular death rate among young and middle aged men in Russia cannot simply be dismissed as coding artefact.

\section{ACKNOWLEDGEMENTS}

We would like to express our sincere gratitude to forensic experts of the Bureau for Forensic Expertise of the Udmurt Republic Viktor Jikhorev, Takhir Zakhirov and Dmitiy Koshkin. We are also very grateful to Nina Andriyanova from the Centre for Demography and Human Ecology in Moscow for her extensive contribution to data processing.

Funding: this study was funded by the United Nations Development Programme.

\section{Authors' affiliations}

V M Shkolnikov, Max Planck Institute for Demographic Research, Rostock, Germany

M McKee, European Centre on Health of Societies in Transition, London School of Hygiene and Tropical Medicine, London, UK

V V Chervyakov, Transnational Family Research Institute, Moscow, Russia

N A Kyrianov, Izhevsk State Medical Academy, Izhevsk, Russia

\section{REFERENCES}

1 Leon D, Chenet L, Shkolnikov VM, et al. Huge variation in Russian mortality rates 1984-1994: artefact, alcohol, or what? Lancet 1997;350:383-8.

2 Walberg P, McKee M, Shkolnikov V, et al. Economic change, crime, and mortality crisis in Russia: a regional analysis. BM

1998;317:312-18.
3 Shkolnikov V McKee M Leon DA. Changes in life expectancy in Russia in the 1990s. Lancet 2001;357:917-21.

4 Renaud S, Crigui MH, Farchi F, et al. Alcohol drinking and coronary heart disease. In: Vershuren PM, ed. Health issues related to alcohol consumption. Washington DC: ILSI Press, 1993.

5 Britton A, McKee M. The relation between alcohol and cardiovascular disease in Eastern Europe: explaining the paradox. J Epidemiol Community Health 2000;54:328-32.

6 Shestov DB, Deev AD, Klimov AN, et al. Increased risk of coronary heart disease death in men with low total and low-density lipoprotein cholesterol in the Russian Lipid Research Clinics Prevalence Follow-up Study. Circulation 1993;88:846-53.

7 McKee M, Britton A. The positive relationship between alcohol and hear disease in eastern Europe: potential physiological mechanisms. J $R$ Soc Med 1998:91:402-7.

8 Bobak M, Marmot M. Alcohol and mortality in Russia: is it different than elsewhere? Ann Epidemiol 1999;9:335-8.

9 McKee M, Shkolnikov V, Leon DA. Alcohol is implicated in the fluctuations in cardiovascular disease in Russia since the 1980s. Ann Epidemiol 2001;11:1-6.

10 Tishuk EA. Mediko-statisticheskiye aspekti deistviya alkogolya kak prichini smertnosti naseleniya [Medical statistical aspects of alcohol's action as a cause of death in the population]. Zdravoohraneniye Rossiyskoi Federatsii 1997:2:34-6.

11 Shkolnikov VM, Chervyakov VV, eds. Policies for the control of the transition's mortality crisis in Russia. Moscow: UNDP/Russia, 2000.

12 Kaufman JS, Asuzu MC, Rotimi CN, et al. The absence of adult mortality data for sub-Saharan Africa: a practical solution. Bull World Health Organ 1997:75:389-95.

13 Shkolnikov VM, Meslé F, Leon DA. Premature circulatory disease mortality in Russia: population- and individual-level evidence. In: Weidner G, Kopp M, Kristenson M, eds. Heart disease: environment, stress and gender. Amsterdam: IOS Press (in press).

14 Spravochnik po kliniko-ekspertnoi rabote. [Manual for clinical expert work]. Moscow: Grant, 1998.

15 Ministry of Health of the Russian Federation. Directive no 407 of 10.12.1996. On the introduction into the practice of the rules for forensic expertise. Moscow: Ministry of Health, 1996.

16 Poikolainen K. Alcohol poisoning mortality in four Nordic countries. Helsinki: The Finnish Foundation for Alcohol Studies, 1977.

17 Guideri G, Gutstein WH, Olivetti G, et al. Effects of alcohol on isoproterenol-induced ventricular fibrillation in adult rats. J Cardiovasc Pharmacol 1998;12:479-85.

18 Hillbom M, Kangasaho M, Löwbeer $C$, et al. Effects of alcohol on platelet function. Alcohol 1985;2:429-32.

19 Poikolainen-K. Estimated lethal ethanol concentrations in relation to age, aspiration, and drugs. Alcohol Clin Exp Res 1984;8:223-5.

20 World Health Organisation. Health for All database. Copenhagen: WHO, 2001. 